\title{
A busca da felicidade: Nosso erro, ilusão e existência fundamentais, segundo Schopenhauer
}

\author{
Guilherme Marconi Germer \\ Doutorando em Filosofia pela UNICAMP, bolsista da FAPESP \\ E-mail: guilhermeguita@uol.com.br
}

\begin{abstract}
RESUMO: Schopenhauer define a felicidade como a "satisfação sucessiva de todo o nosso querer", e afirma que a tendência a ela (i) "coincide completamente com a nossa existência" - cuja essência é a Vontade de viver - mas (ii) é revelada pelo conhecimento como o nosso maior erro e ilusão. Com base nisso, ele defende que (i) o propósito da vida consiste na busca da felicidade, mas (ii) o "verdadeiro objetivo" é a infelicidade - que é imposta pelo "destino" e conduz à auto-supressão da Vontade. Neste artigo, primeiro se apresentará ambos os aspectos da busca da felicidade, e depois se sugerirá que não há contradição nem unilateralidade no filósofo, mas uma visão dualista dos atos fundamentais da essência humana - a Vontade: (i) auto-afirmação - gula cega e incondicional por... (felicidade plena) - e (ii) auto-negação de si própria - na qual essa sede hedonista é compreendida como um erro.
\end{abstract}

PALAVRAS-CHAVE: Pessimismo, hedonismo, soteriologia.

ABSTRACT: Schopenhauer defines happiness as the "successive satisfaction of all of our wanting", and argues that the tendency for it (i) " completely coincides with our existence" - whose essence is the will to live - but (ii) is revealed by knowledge as our biggest mistake and disillusion. On these basis, he argues that (i) the purpose of life is the pursuit of happiness, but (ii) the "real goal" is unhappiness - which is imposed by "destiny" and leads to the self-suppression of the will. We will first introduce both aspects of the pursuit of happiness to then suggest that there is neither contradiction nor unilaterality in the philosopher, but a dualistic view of the fundamental acts of the human essence - the will: (i) self-affirmation - blind and unconditional greedyness for... (complete happiness) - and (ii) self-denial - in which this hedonistic thirst is understood as an error.

KEYWORDS: Pessimism, hedonism, soteriology.

Schopenhauer pensa na busca humana da felicidade com um duplo ponto de vista, a saber: como a expressão tanto do principal erro e ilusão do ser humano como da base de sua existência. Nas primeiras palavras do Capítulo 49 - O Caminho da Salvação - de Die Welt als Wille und Vorstellung (O Mundo como Vontade e Representação) - Tomo II, esta aparente ambigüidade salta à vista - como se lê a seguir: 
Há apenas um erro inato, e este é o de que nós existimos para sermos felizes. Ele é inato em nós porque coincide com a nossa própria existência e porque, de fato, todo nosso ser é apenas a sua paráfrase, assim como nosso corpo é o seu monograma: nós somos justamente Vontade de viver, e na satisfação sucessiva de todo o nosso querer é em que pensamos mediante a noção da felicidade. Enquanto nós persistimos neste erro, e ainda por cima corroboramo-lo com dogmas otimistas, o mundo nos parece cheio de contradições. Assim, a cada passo, nas grandes ou nas pequenas coisas, somos obrigados a experimentar que o mundo e a vida estão completamente arranjados de modo a não conterem a existência feliz (...) Neste sentido, seria mais correto colocar o objetivo da vida em nossas dores do que nos prazeres... A dor e a aflição trabalham em direção ao verdadeiro objetivo da vida, a supressão da Vontade dela ${ }^{1}$.

Assim, Schopenhauer define a noção da felicidade como a "satisfação sucessiva de todo o nosso querer" e afirma que a tendência a ela, por um lado, coincide completamente com a nossa existência - cuja essência é a Vontade de viver - mas por outro, é revelada pela experiência como o nosso maior erro e desilusão. Como conseqüência do primeiro aspecto mencionado, tem-se que o propósito da vida consiste na busca da felicidade. Como conseqüência do segundo, porém, o "verdadeiro objetivo" é, antes, a infelicidade, já que essa pode conduzir à bem-aventurada auto-supressão da Vontade de viver. Haveria, diante disso, uma flagrante contradição no filósofo? No decorrer deste artigo defender-se-á que não, mas que ele apenas defende uma visão dualista dos atos fundamentais da essência do ser humano, a Vontade. Em outras palavras, que ele entende que a vida humana possui o caráter "estranho e ambíguo" de ter em seu âmago dois propósitos fundamentais diametralmente opostos: o que busca cegamente a felicidade e o que ensina de modo fatídico e mortificador que ela inexiste. Antes disto, se analisará e interpretará ambos as noções e se discordará da crítica de que o pessimismo schopenhaueriano seja unilateral.

\section{II}

Em sua metafísica da natureza, Schopenhauer afirma que a Vontade de viver é a essência íntima e comum de todos os animais, vegetais e minerais. Segundo o filósofo, as espécies de animais consistem nos graus mais elevados de sua objetivação, cujos fenômenos revelam, portanto, da maneira mais nítida e aguda a essência da Vontade. Qual

\footnotetext{
${ }^{1}$ WWV II, p. 813.
} 
é esta essência? O que quer a Vontade de viver? Quer "existência, bem-estar, vida e propagação"2. Ela quer exatamente este mundo mesmo, tal qual se nos apresenta: nada divino ou "espiritual", como quer Hegel, mas antes, terrível e demoníaco. Nos graus mais rudimentares e pétreos de sua manifestação, a Vontade conserva a sua natureza de "ímpeto cego", "esforço contínuo", "carente de conhecimento"3, "fim e limite"4. É neste sentido derivado e metafísico, portanto, que Schopenhauer vê tanto o mundo inorgânico quanto o orgânico como a manifestação de uma Vontade de viver una, atemporal e livre, que responde positivamente pelo conceito negativo de Kant da coisa em si. Por fim e resumidamente, segundo o pensador, a essência da natureza é essa Vontade de viver, coração real e empírico do mundo, e não umas tais “Alma do mundo" racional, Deus, Absoluto e etc. - que são tão estranhos, distantes e supérfluos à mesma. Com as seguintes palavras ele defende esta concepção e polemiza com os "teólogos enrustidos de filósofos" de sua época:

Cada relance do mundo (...) confirma e evidencia que a Vontade de viver (...) é a única expressão verdadeira de sua essência mais íntima. Tudo impele e pressiona pela existência, se possível, pela existência orgânica, isto é, pela vida, e assim por seus graus mais elevados possíveis: na natureza animal, torna-se evidente que a Vontade é a tônica fundamental de sua essência, a sua única propriedade imutável e incondicionada. Considere-se este ímpeto de vida universal, veja-se a infinita solicitude, facilidade, exuberância com que a Vontade de viver pressiona pela existência impetuosamente, sob milhões de formas em todos os lados e momentos, mediante fecundações e germinações - ou onde disso carece por 'generatio aequivoca' (geração espontânea), agarrando cada oportunidade, usurpando cobiçosamente cada material passível de vivificação. Que se lance ainda um olhar ao alarme terrificante e à rebelião selvagem de algo cujo fenômeno, por alguma razão, deve deixar a existência - especialmente onde isto é vivenciado com perfeita consciência (...) Neste fenômeno torna-se manifesto que eu nomeei corretamente a Vontade de viver como aquilo incapaz de novas explicações, mas que é a base de toda explicação; e que, longe de ser uma palavra vazia, como o Absoluto, o Infinito, a Ideia e outras similares, é a coisa mais real que nós conhecemos, é, de fato, o cerne de toda a realidade ${ }^{5}$.

\footnotetext{
2 WWV II p. 263.

3 WWV I, p. 221. MVR I, p. 214.

4 Ibid, p. 171. Ibid, p. 169.

5 WWV II, p. 452.
} 
Schopenhauer ensina que quando observamos a manifestação dessa Vontade de viver nos seres humanos e nos demais animais, vemos que ela aparece, em primeiro lugar, como um "esforço para a conservação do indivíduo". Contudo - ele prossegue - "isto é apenas um degrau para o esforço pela conservação da espécie, a qual em última instância deve ser mais violenta, já que a vida da espécie supera a do indivíduo em duração, extensão e valor"6. Em palavras mais categóricas e trágicas: "A natureza tem apenas um propósito, a saber, a manutenção de todas as espécies (...) O indivíduo tem para ela apenas um valor indireto, na medida em que é um meio à manutenção das espécies"7 ${ }^{\text {7 }}$ Segundo o pensador, este aspecto da natureza evidencia bem a radicalidade da Vontade de viver: essa "quer a vida absoluta e eternamente", assim, completa o impulso de auto-preservação com o sexual, "que tem em vista uma série infinita de gerações" ". Deste modo, o filósofo concebe a vida dos animais como dedicada integralmente a duas coisas básicas: alimentação e reprodução. Uma "infinitude de variedades de formas", correspondentes aos "elementos e modos de vida" mais específicos e compostas pelos mecanismos e estruturas mais ingênuas e perfeitas. Um gasto incalculável e incessante de "atividade, força, habilidade e astúcia". Uma inadequação geral entre "aquilo que é exigido e aquilo que é obtido". "Sofrimento grande e duradouro, conflito constante, 'bellum omnium', todos são caçadores e todos são caças, pressão, desejo, necessidade e ansiedade. Berros e uivos" animalidade. E em nome de quê tudo isto? Basicamente, de "nutrição e procriação, os quais são apenas os meios à continuação e ao reinício em um novo indivíduo do mesmo curso melancólico" - assina o pessimista. Ora, onde está a recompensa de todo este esforço incessante? Ou ao menos a justificativa: por que tudo isto? "Porque assim a Vontade se objetiva".

\section{III}

Na metafísica dos costumes, Schopenhauer propõe-se a interpretar e explicitar o “agir humano e suas diversas e até mesmo opostas máximas, das quais ele é expressão viva,

\footnotetext{
${ }^{6}$ Ibid., p. 656.

${ }^{7}$ Ibid., p. 453.

${ }^{8}$ Ibid., p. 726.

${ }^{9}$ Ibid., p. 354.
} 
de acordo com sua essência mais íntima e conteúdo"10. Segundo o filósofo, neste lado as coisas ficam "mais sérias", pois - subjetivamente - o objeto da investigação - o ser humano - "afeta de maneira imediata a cada um de nós e a ninguém pode ser alheio ou indiferente" - e objetivamente - ele é o grau mais elevado de manifestação da Vontade, no qual ela conhece-se a si própria, afirma-se ou nega-se a si mesma. Assim, Schopenhauer encontra na existência humana a mesma essência animal em um grau mais delicado e extremo. Segundo a sua descrição, se a Vontade de viver se exibisse no ser humano como um mero impulso pela auto-conservação, suas preocupações e problemas "não seriam grandes, e conseqüentemente sua existência seria fácil e alegre"11. Contudo, como ela também se apresenta como pulsão sexual - por meio da qual ambiciona pela afirmação infinita - ela remove da consciência a "despreocupação, alegria e inocência" e a inunda de "inquietude, dificuldade e melancolia”. Mais precisamente, o pensador assevera que a essência da sexualidade repousa no seguinte encantamento: a natureza, preocupada apenas com a manutenção das espécies, amiúde encontra por obstáculo o egoísmo humano; assim, quando ela precisa que o "indivíduo seja ativo e faça sacrifícios em nome da continuação e constituição da espécie", implanta nele "uma certa ilusão, por meio da qual o que, na realidade, só é bom à espécie lhe parece ser algo bom para si próprio”. Com isto - descreve o alemão - o indivíduo acaba "servindo à espécie, embora sob a ilusão de servir-se a si próprio. Neste processo, uma mera quimera, que depois desaparece imediatamente, paira sobre ele, e, como motivo, toma o lugar da realidade. Esta quimera é o instinto". Conforme este pensamento, é completamente equivocado dizer que o ser humano não possui instintos. Afinal, a escolha tão "fina, séria e caprichosa" que as pessoas fazem de seus parceiros sexuais repousa em um instinto "bem determinado, distinto e complicado"12. De acordo com o filósofo, a beleza e a feiúra do outro indivíduo não têm nada a ver com a "satisfação em si", isto é, com a satisfação de um "prazer sensual baseado em uma necessidade individual e urgente". Em última instância, beleza e feiúra não "se relacionam diretamente com o escolhedor em si... mas com o verdadeiro objetivo: com aquilo que está por ser criado, uma vez que nele o tipo da espécie deve ser mantido do modo mais puro e autêntico possível"13. Sendo assim, Schopenhauer defende que o ato sexual, consumado após tanta

\footnotetext{
10 Ibid., p. 377.

11 Ibid., p. 568.

${ }^{12}$ Ibdem.

13 Ibid., p. 689.
} 
ansiedade e privação, sempre é seguido do desaparecimento da miragem sedutora da natureza e da desilusão do indivíduo, o qual se sente enganado por ela. Segundo o seu critério, o benefício arduamente conquistado pelo indivíduo pertence à espécie e não entra na sua consciência como o anseio por ele. Com as seguintes palavras o pensador descreve esse ilusionismo da paixão humana e a sua incontornável decepção final:

$\mathrm{O}$ encanto vertiginoso e mentiroso que assalta o homem ao ver uma mulher que ele considere bela, e que o ilude de que a unificação com ela é o mais elevados dos bens - é o sentido da espécie (...) Assim, os seres humanos presumem fazer esforços e sacrifícios para a sua própria satisfação, mas servem apenas à manutenção do tipo regular da espécie ou a uma individualidade completamente determinada, cuja existência só pode ser alcançada a partir de tais pais (...) Conseqüentemente, depois do prazer finito obtido, todos os apaixonados experimentam uma estranha desilusão, e se espantam com o fato de que aquilo desejado tão ardentemente não produz nada mais do que quaisquer outros prazeres sexuais $^{14}$.

Schopenhauer afirma que as exigências humanas pela auto-conservação e reprodução são tão severas que o homem é merecidamente reconhecido como o "mais necessitado de todos os seres". Segundo o filósofo, o ser humano é "querer concreto, necessidade absoluta, concretização de milhares de necessidades" ${ }^{15}$. Contudo, quando a sua milagrosa existência é momentaneamente protegida dos perigos, conservada e assegurada, as pessoas "não sabem o que fazer com ela", e são assaltadas, portanto, pelo "empenho em livrar-se do lastro da existência, torná-la não sensível, 'matar o tempo', isto é, escapar do tédio" ". Com base nisso, o filósofo afirma que a vontade humana "oscila como um pêndulo, para aqui e para acolá" entre estes dois "componentes básicos": a dor e o tédio. Por conseguinte, o anseio humano pela "satisfação sucessiva de todo o querer" - a saber, pela "felicidade" - significa, na "prática", a busca da menor quantidade possível de dor e tédio; isto é, da fronteira média, do instante passageiro entre estes dois pólos da vontade. Em outras palavras, o decurso da vida é o mais feliz possível "quando o desejo e a satisfação se alternam em intervalos nem muito curtos" - o que engendra o tédio - nem

\footnotetext{
${ }^{14}$ Ibid., p. 540.

15 Ibid., p. 428.

${ }^{16}$ Ibid., p. 429.
} 
muito longos - o que provoca a miséria ${ }^{17}$. Resumidamente, a felicidade é volátil, inapreensível, ou melhor, negativa. E desta perspectiva, segue-se ser incompreensível que as pessoas gastem tantos esforços e lutem contra tantos inimigos pela felicidade; que considerem-na um direito legítimo e justificado seus, e acreditem que ela nunca é alcançada, ou só muito raramente, por uma mera questão de azar ou de injustiça. Verdadeiramente: apenas uma Vontade cega pode motivá-las. Com as seguintes palavras esse absurdo da busca da felicidade é denunciado pelo pessimista:

Tudo na vida proclama que a felicidade terrena está destinada a ser frustrada, ou reconhecida como uma ilusão. Os fundamentos disto dormem nas profundezas da natureza das coisas (...) A felicidade comparativa é geralmente apenas aparente, ou então, como a longevidade, uma exceção. A sua própria possibilidade deveria ser abandonada, como um mero chamariz (...) A felicidade repousa sempre no futuro, ou em todo caso no passado, e o presente pode ser comparado a uma pequena nuvem negra conduzida pelo vento sobre a planície ensolarada: atrás e na frente dela tudo é brilhante, apenas abaixo de si sempre há só sombra (...) É difícil conceber como que alguém pode (...) ser persuadido de que (...) o homem exista para ser feliz. Pelo contrário, estas decepções e desilusões contínuas, como a natureza geral da vida, apresentam-se como que destinadas e calculadas para despertar a nossa convicção de que (...) a vida é uma empresa que não cobre os seus custos; e que a nossa vontade deveria virar as costas para ela.

Qual é o "fundamento" último da ilusão da felicidade que Schopenhauer afirma “dormir nas profundezas da natureza das coisas"? Sobretudo, o fato de que a felicidade e o prazer são negativos, enquanto apenas a dor e o sofrimento são positivos. O que esta tese quer dizer? Antes de mais nada, o que ela não quer dizer é que a felicidade e o prazer não existam como eventos psicológicos, pois eles existem, esporadicamente. Pelo contrário, o que Schopenhauer defende é que a felicidade e o prazer não podem apresentar-se por si sós e originariamente, pois devem sempre ser a libertação de um desejo, de uma carência, uma necessidade ou mesmo do "mortífero tédio" são negativos, enquanto que o desejo, a dor, o vazio e o tédio são originais e positivos. O filósofo acredita confirmar esta tese nos seguintes fenômenos psicológicos:

\footnotetext{
${ }^{17}$ Ibidem.

${ }^{18}$ WWV I, p. 438. MVR I, p. 411.
} 
Nós sentimos dor, mas não sentimos a falta de dor; sentimos a preocupação, mas não a falta de preocupação; sentimos o medo, mas não a segurança. Nós sentimos o desejo, como sentimos a fome e a sede; mas tão logo ele é satisfeito, ocorre o mesmo que com o bocado de comida: no instante em que é devorado, desaparece aos nossos sentimentos (...) Por isto, nós não somos conscientes dos três maiores bens da vida - a saúde, a juventude e a liberdade - quando os possuímos, mas somente depois de perdê-los: pois também eles são meras negações (...) As horas se vão mais rápido quanto mais prazenteiras são; e mais devagar quanto mais penosas: isto porque a dor, e não o prazer, é positiva e faz o seu presente sensível. Do mesmo modo, com o tédio nos tornamos conscientes do tempo, com o divertimento e o passa-tempo não. Ambos os casos demonstram que a nossa existência alcança o máximo de felicidade quando a sentimos o mínimo possível: disto se segue que o melhor seria não possuir a existência ${ }^{19}$.

Consequentemente, Schopenhauer afirma que tudo ao nosso redor cheira a enxofre: “tudo é imperfeito e decepcionante, todo agradável está mesclado com algo de desagradável, todo prazer é apenas meio-prazer, toda satisfação introduz a sua própria perturbação, todo alívio engendra novas moléstias" ${ }^{20}$. Conforme a sua lição, dois remédios foram recomendados contra o sofrimento: "a prudência, a precaução e a astúcia", por um lado, e a equanimidade estóica, por outro ${ }^{21}$. Mas ambos se revelaram insuficientes e "a verdade é que nós devemos ser infelizes, e assim o somos". Até aqui, sequer foi mencionada a "fonte principal do mal mais sério que acomete o ser humano", a saber, ele mesmo: “Homo homini lupus' (O homem é o lobo do homem)”22. De acordo com Schopenhauer, "a conduta geral dos seres humanos entre si é caracterizada via de regra pela

\footnotetext{
19 WWV II, p. 575.

${ }^{20}$ Ibid., p. 739.

${ }^{21}$ Ibid., p. 577. No Livro I de $O$ Mundo..., Schopenhauer elogia a sabedoria estóica como o "ápice a que o homem pode chegar mediante o simples uso da razão" na questão da felicidade. Segundo a sua interpretação, o estoicismo parte da concepção de que o sofrimento e a felicidade provêm, respectivamente, da desproporção e da proporção entre o querer-ter e o ter, e conclui-se com as seguintes lições: por um lado, que o sofrimento se origina basicamente da cobiça e do desejo - ou seja: "Não é a miséria que dói, mas a cobiça" - como explicita Epicteto; e por outro, que a felicidade é mais facilmente encontrada com a diminuição do querer-ter - que só depende de nós - do que com o aumento do ter - que é sempre acidental, volátil e, em última instância, sempre temos muito pouco. Contudo, a despeito desta homenagem ao estoicismo, o alemão não comunga de sua fé otimista no poder racional de autocontrole, e objeta-a com as seguintes palavras: "Ainda assim falta muito para que (...) a razão, corretamente empregada, possa livrar-nos de todo fardo $e$ sofrimento da vida e conduzir-nos à bem-aventurança. Antes, verifica-se uma completa contradição em querer viver sem sofrer (...) Essa contradição se manifesta naquela ética da razão pura já pelo fato do estóico ser forçado a incluir em seu preceito para uma vida feliz (pois a isto se refere sempre sua ética) uma recomendação de suicídio (...) A sabedoria estóica nunca pôde ganhar vida ou verdade poética interior, mas permaneceu um boneco de madeira com o qual não se pôde fazer nada. WWV I., p. 147. MVR I, p. 148.

${ }_{22}$ PLAUTUS, Asinaria, 2. Apud SCHOPENHAUER, WWV II, p. 577.
} 
injustiça, deslealdade extrema, dureza e mesmo crueldade: o oposto disto aparece apenas como exceção" 23 . E daí a necessidade da auto-repressão humana por meio do Estado, da legislação, das religiões e do implacável juízo público. Ademais, o filósofo destaca que a terrível inveja que habita em todos nós também evidencia o quão infeliz a sociedade é. Pois do contrário, as pessoas não necessitariam contaminar com tanta prontidão os méritos e bens alheios. Por fim, o pensador entende que há ainda um último aspecto absolutamente essencial da existência que sela o seu completo caráter de erro: a morte.

\section{IV}

Como se apresentou anteriormente, Schopenhauer afirma que o ser humano é iludido pela natureza com a miragem de que o laço erótico com a pessoa amada é o bem supremo do universo. Conforme o seu pensamento, nas antípodas desta ilusão está a morte, que é, pois, "o maior de (todos) os maus... a pior coisa que em todos os lados pode nos ameaçar", e "o mais terrível de todos os medos"24. Segundo o pessimista, é principalmente pelo medo da morte, e não propriamente pelo amor à vida, que o ser humano agarra-se tão firmemente a essa e, amiúde, adia o seu fím com toda força e dor possíveis. Assim, se a sexualidade é "a mais decidida expressão da Vontade de viver (...) é o cerne, o compêndio, a quintessência do mundo", a morte é "o resultado, o resumo da vida; a soma que expressa em um só golpe toda a lição que ela dá em partes e isoladamente, a saber, que todo o esforço de cujo fenômeno é a vida é vão, frívolo e auto-contraditório, e que o retorno dele só pode ser encarado como uma salvação" 25 . Em face da presença fundamental da morte até mesmo à vida irracional - que embora não conhece-a, teme-a - e de sua cotidiana vitória sobre o corpo humano, Schopenhauer concorda com o "pressentimento" de Jacob Böhme de que "todos os corpos humanos e animais, todas as plantas, estão de fato parcialmente mortos"26. Do ponto de vista empírico - destaca o pensador - a intuição do místico é corroborada pela vida do corpo humano, a qual "não é senão um morrer continuamente evitado, uma morte sempre adiada"; até que no fim essa vence irresistivelmente, pois a ela "estamos destinados e ela apenas brinca um instante com a sua presa antes de devorá-la".

\footnotetext{
23 Ibid., p. 578.

24 Ibid., p. 593. 467.

25 Ibid., p. 817.

26 WWV I, p. 217. MVR I, p. 211.
} 
Do ponto de vista metafísico, porém, o envelhecimento e a morte são a "sentença de condenação dada pelas mãos da própria natureza à Vontade de viver"27, e que diz o seguinte: "O que você desejou termina assim: deseje algo melhor". De acordo com o filósofo, a morte é uma conseqüência do tempo, e esse é a forma primordial pela qual a "nulidade de todas as coisas aparece como transitoriedade, já que é por meio dele que todos os nossos prazeres e bens tornam-se nada em nossas mãos”. Assim, Schopenhauer conclui que o tempo é o principal responsável pela nulidade da existência, ao passo que a morte é a “confirmação final de que todo o anseio e querer é um caminho equivocado". O que é declamado magistralmente por Rochester a seguir:

Then old age and experience, hand in hand, Lead him to death, and make him understand, After a search so painful and so long, That all his life he has been in the wrong ${ }^{28}$.

\section{V}

Se alguém se fixasse nestas últimas considerações, poderia interpretar que Schopenhauer confere um valor superior à morte sobre a vida, e que, de modo mais geral, a sua descrição pessimista da existência e o seu "descarte da felicidade parece perversamente unilateral". J. Dienstag faz a primeira dessas afirmações ${ }^{29}$ e C. Janaway a segunda ${ }^{30}$. Ambas certamente possuem a influência de F. Nietzsche. Contudo, há algumas dificuldades nestas interpretações, dentre as quais destacam-se as seguintes:

De fato, Schopenhauer defende que a morte possui um "status superior" à vida do indivíduo, por tudo o que se apresentou anteriormente. Por outro lado, ele assevera que a morte e a transitoriedade pertencem a um ponto de vista "empírico, imparcial e objetivo",

\footnotetext{
${ }^{27}$ WWV II, P. 734.

28 "Assim a velhice e a experiência, de mãos dadas / Ensinam-no, conduzindo-o ao fim de sua estrada / Depois de uma busca tão longa e tão sofrida / Que toda a sua vida esteve equivocada" (Tradução nossa).

${ }^{29}$ J. Dienstag defende isto ao comparar as concepções de Schopenhauer e Freud sobre a oposição entre morte e vida. Com ele escreve a seguir: "Opostos aos instintos originais de morte - como Freud os denomina estão os instintos sexuais que preservam a vida (...) O resultado é um conflito sem fim entre vida e morte, travado como uma batalha instintual na psique. Novamente, me parece bem claro que Freud tomou uma noção metafisica de Schopenhauer e a elaborou com o que denomina por termos 'metapsicológicos'. Mas a diferença é que estes dois oponentes possuem agora o mesmo status; a vida não é uma ilusão". DIENSTAG, J. F.. Pessimism. Princeton: Princeton University Press, 2006. P. 105.

${ }^{30}$ JANAWAY, Christopher. Schopenhauer's Pessimism. In: JANAWAY, Christopher (Org.). The Cambridge Companion To Schopenhauer. Cambridge: Cambridge University Press, 1999, p. 332.
} 
que não passa, contudo, de um fenômeno condicionado pelo intelecto, relativo e aparente. Segundo o pensador, é um absurdo flagrante, um véu encobridor da verdadeira natureza das coisas o prisma de que os seres mais perfeitos da natureza, a saber, os vivos "nasçam das profundezas com suas organizações infinitamente complicadas e incompreensivelmente engenhosas, e, após um curto lapso de tempo, devam tornar-se absolutamente nada, para ceder lugar a novos semelhantes igualmente advindos do nada" ${ }^{31}$. Conforme o filósofo, quem aprendeu a lição idealista de Platão e dos Upanishads e busca nas coisas não o seu particular, mas o universal e as Ideias, será tomado pela "convicção imediata e certa" de que embora a vida individual seja uma ilusão passageira, a vida das espécies e a Vontade de viver são perpétuas. De acordo com esta perspectiva, a natureza não se importa com a queda individual, pois sabe que essa implica o eterno retorno ao seu ventre, onde tudo está "seguro e a salvo"32 e "o mesmo caminho continua em aberto" ${ }^{33}$. Esta conclusão pode ser obtida de modo "fundamental e cru" - afirma o pensador - a partir da dedução de que tanto as forças naturais (dentre as quais a vontade humana) como a matéria são condições $a$ priori das transformações, e assim, imunes às mesmas. Porém, o metafísico enfatiza que essa mesma intuição pode ser experimentada com a audição do "todo" da natureza, a qual "é sincera e franca, nunca mente... apenas se expressa no estilo lacônico do oráculo" ${ }^{34}$. Segundo o seu pensamento, a natureza ensina que o nascimento e a morte pertencem ao indivíduo fenomênico, enquanto que a Vontade de viver é eterna e infinitamente presente como se constata a seguir:

Tudo persiste apenas um instante e apressa-se à morte. A planta e o inseto morrem no fim do verão, o animal e o homem depois de alguns anos: a morte ceifa infatigavelmente. Contudo, como se isto não fosse o caso em sua totalidade, tudo está sempre lá, imperecivelmente, em seu lugar e posição. Eternamente a planta verdeja e floresce, o inseto assobia, o animal e o ser humano seguem em juventude indestrutível, e em todo verão temos para nós as mesmas cerejas que já foram saboreadas milhares de vezes. Também os povos permanecem ali, como indivíduos imortais; se por ventura trocam de nome, o seu agir, o seu esforço e o seu sofrimento continuam os mesmos (...) A espécie é pois o que vive em todos os tempos, e na consciência de sua perenidade e na identidade com ela os indivíduos vivem bem dispostos. A Vontade de viver se manifesta

31 WWV II, p. 606.

${ }^{32}$ Idem.

33 Ibid., p. 599.

${ }^{34}$ Ibid., p. 607. 
no presente infinito; pois essa é a forma da vida da espécie, a qual, portanto, não envelhece, mas permanece sempre jovem. A morte é para ela o que o sono é para o indivíduo (...) Do mesmo modo que o mundo desaparece com a chegada da noite, mas em nenhum instante deixe de existir por isto; os homens e animais também apenas aparentemente expiram com a morte, muito embora os seus verdadeiros seres persistam imorredouramente ${ }^{35}$

Assim, o pessimismo de Schopenhauer não é unilateral quanto ao tema da morte. Segundo ele, a vida individual é uma ilusão em face da morte e da transitoriedade, mas essas, por sua vez, são ilusões diante da vida das espécies e da Vontade de viver. A compreensão deste duplo ponto de vista facilita a de outro um pouco mais difícil, concernente à questão da busca da felicidade: conforme o pessimista, por um lado, o sofrimento, o envelhecimento e a morte têm "status superior" à perseguição individual da fortuna, ensinando que essa é "um caminho equivocado". Por outro lado, porém, a Vontade de viver é cega e imperatriz de seu presente infinito, logo, pode ignorar perfeitamente a sabedoria mortificadora da vida e manter, auto-afirmativamente, a sua gula irresistível por... (felicidade plena). Ao radicalizar este segundo lado, o filósofo afirma que a Vontade, considerada do modo mais íntimo, não é posta em movimento por nenhum fundamento ou motivo externo, mas por sua própria "cegueira" radical que pode querer este mundo mesmo com todo o sofrimento e transitoriedade. De fato, a Vontade é una. Mas apresenta dois atos fundamentais: auto-afirmação - perseguidora incondicional de prazer e felicidade - e auto-negação de si própria - na qual essa sede volitiva é compreendida e negada como um erro. Com as seguintes palavras o pensador descreve a miopia do primeiro ato e a sua antecedência sobre o conhecimento do caráter errático da vida:

Objetivamente, a Vontade de viver nos aparece (...) como uma tolice, e subjetivamente, como uma desilusão. Desde este ponto de vista, todo ser vivo trabalha com a extrema fadiga de suas forças por algo que não possui valor algum. Contudo, em uma consideração mais íntima, nós percebemos que a Vontade é uma pulsão cega, um impulso completamente destituído de fundamentos e motivos (...) Sendo assim, ao compararmos, como fizemos atrás, os esforços incansáveis, sérios e laboriosos dos homens com o que eles obtêm disso, ou mesmo com o que eles podem obter disso, a desproporção resultante é somente aparente, já que nós reconhecemos que o que deve ser obtido, enquanto poder motivacional, é completamente inadequado para explicar este movimento e atividade incansável (...) A

35 Ibid., p. 611. 
partir da natureza original e incondicional da Vontade (...) é fácil explicar que os homens amem acima de tudo uma existência cheia de desejos, problemas, sofrimentos, ansiedades e tédio, e que se fosse ponderada e considerada objetivamente, ele necessariamente repudiaria (...) A Vontade de viver não é uma conseqüência do conhecimento da vida (...) mas aquilo que é primeiro e incondicionalmente ${ }^{36}$.

Muitos comentadores e críticos de Schopenhauer não observam precisamente este reconhecimento do filósofo do caráter "primeiro e incondicionado" da auto-afirmação da Vontade, cuja expressão abstrata, subjetiva e humana é a busca da felicidade. De acordo com o dualismo schopenhaueriano, a saga antropológica é o palco do conflito de dois propósitos fundamentais e radicalmente opostos: de um lado, o da busca cega e individual pela felicidade (auto-afirmação da Vontade) - e de outro, o imposto pelo destino do sofrimento, que é um dos princípios da auto-negação da Vontade de viver. Com as seguintes palavras o pensador defende a ambigüidade e a absurdidade do conflito essencial destes dois propósitos volitivos:

O que dá à vida o seu caráter estranho e ambíguo é que nela dois propósitos fundamentais e diametricamente opostos se cruzam constantemente: o da vontade individual, direcionado à felicidade quimérica em uma existência efêmera, onírica e ilusória (...) E o propósito do destino, endereçado com suficiente evidência à destruição de nossa felicidade, e por meio disso, à mortificação de nossa vontade e à supressão da ilusão que nos mantém atados aos laços deste mundo ${ }^{37}$.

Posteriormente, S. Freud vai defender uma posição analogamente dualista e pessimista no concernente à busca da felicidade, que provavelmente teve a influência de Schopenhauer. Em O Mal Estar na Civilização, ele afirma que, por um lado, a busca da felicidade é o grande propósito da vida, mas por outro, que "todas as normas do universo são-lhe contrárias" e a felicidade parece não haver sido "incluída no plano da "Criação"”. Essa concordância dualista e pessimista tem raízes bem profundas: em Além do Princípio do Prazer, após uma longa especulação baseada na observação clínica que não será comentada aqui, Freud defende que a vida anímica é marcada pelo conflito entre dois grupos de pulsões fundamentais: as de vida (Eros) e as de morte. Após a exposição dessa teoria, o cientista reconhece a concordância com o filósofo da Vontade com as seguintes

\footnotetext{
36 Ibid., p. 462.

37 Ibid., p. 820.
} 
palavras: "Inadvertidamente voltamos nosso curso para a baía da filosofia de Schopenhauer. Para ele, a morte é o 'verdadeiro resultado e, até esse ponto, o propósito da vida', ao passo que o instinto sexual é a corporificação da vontade de viver" ${ }^{38}$. No que toca aos atos ou pulsões fundamentais, portanto, Freud é mais herdeiro de Schopenhauer do que o próprio Nietzsche: pois esse nega a auto-negação da Vontade, assim como Jung ignora a pulsão de morte freudiana. Em termos bem gerais e finais, Schopenhauer e Freud são dualistas neste aspecto, Nietzsche e Jung "monistas", com o que metade da existência se perde desde o primeiro ponto de vista ${ }^{39}$. É verdade que Schopenhauer se estende um pouco mais no comentário e destaque do lado auto-mortificador da vida. Mas a rigor, isto não autoriza a crítica de unilateralidade.

\section{Referências}

DIENSTAG, J. Pessimism. Princeton: Princeton University Press, 2006. 293p.

FAZIO, D., KOSSLER, M., LÜTKEHAUS, L. Arthur Schopenhauer e la sua scuola. Lecce: Pensa Multimedia, 2006.

FAZIO, D., KOSSLER, M., LÜTKEHAUS, L. La Scuola di Schopenhauer: Testi e contesti. Lecce: Pensa Multimedia, 2009.

FREUD, S. Gesammelte werke : chronologisch Geordnet. Frankfurt: S. Fischer, 1991. 18v.

FREUD, S. Obra Completa. Edição Standard Brasileira. Trad. J. Salomão. Rio de Janeiro: Imago, 2009. $24 \mathrm{v}$.

GIACOIA JR., O. Além do princípio do prazer: um dualismo incontornável. Rio de Janeiro: Civilização Brasileira., 2008. 103p.

JANAWAY, C. Schopenhauer's Pessimism. In: JANAWAY, C. (Org.). The Cambridge Companion To Schopenhauer. Cambridge: Cambridge University Press, 1999, p. 318-341.

MONZANI, L. R. O paradoxo do prazer em Freud. In: SIMANKE, R. T. e FULGENIO, L. (Org.). Freud na filosofia brasileira. São Paulo: Escuta, 2005.

\footnotetext{
${ }^{38}$ FREUD, S.. Além do princípio de prazer. In: V. XVIII da ESB. P. 60.

${ }^{39}$ Este é apenas um dos aspectos que dispõem Freud no limite da "escola de Schopenhauer". E sobretudo se neste limite pudermos encontrar - próximo dos filósofos "metafísicos", "hereges" e "pais da igreja", que compõem propriamente a escola segundo a sistematização historiográfica e bem-humorada de D. Fazio, L. Lütkehaus e M. Kossler - os "cientistas" (nos quais Freud se incluiria) e os "artistas". Esta "meia inclusão" concordaria tanto com a aceitação apenas parcial de Freud da aproximação com Schopenhauer, quanto com a compreensão daqueles autores de que a escola propriamente dita de Schopenhauer é composta por filósofos propriamente ditos. Cf. FAZIO, D., KOSSLER, M., LÜTKEHAUS, L.. Arthur Schopenhauer e La sua Scuola. Lecce: Pensa Multimedia, 2006. FAZIO, D., KOSSLER, M., LÜTKEHAUS, L.. La Scuola di Schopenhauer: Testi e contesti. Lecce: Pensa Multimedia, 2009.
} 
Revista Voluntas: estudos sobre Schopenhauer - 2º semestre 2011 - Vol. 2 - № 2 - ISSN: 2179-3786 - pp. 113-127.

SCHOPENHAUER, Arthur. Sämtliche Werke in fünf Bänden. Stuttgart/Frankfurt am Main: Suhrkamp, 1986.

SCHOPENHAUER, Arthur. O mundo como vontade e como representação. Trad. Jair Barboza. São Paulo: Editora Unesp, 2005.

SCHOPENHAUER, Arthur. The World as Will and Representation - Volume II. Trad. E. F. J. Payne. New York: Dover Publications, 1958.

Recebido: $31 / 12 / 11$

Received: $12 / 31 / 11$

Aprovado: 01/02/12

Approved: 02/01/12 